\title{
Sports Management and Opportunities for Professional Development
}

\author{
Mrs. Darshana Rani \\ Assistant Professor Kanya Mahavidyalaya, Kharkhoda, Ph. 9466256824
}

\begin{abstract}
Considering contemporary conditions, the industry associated with sports and management has evidently noticed growth and became even more attractive as a segment where the use of the business based philosophy considering planning and implementation is enforced. Sports structurally analyzed, includes a wide range of activities, processes and human resources from the area of the sports industry, which more extremely is focused on the modernization of management methods and the techniques for attracting and retaining customers.Management procedures used in sports include an extremely wide range, starting from the focus on a specific, particular segment of business operations, such as marketing or financial management in the purpose of sports up to a so called basic usage, or holistic management model, where all aspects of sports management, should be applied.Sports management can theoretically be determined in many ways, but in essence it is a combination of skills related to planning, organizing, coordinating, motivating and controlling in the context of the organization or department whose primary product or service are associated with sports. At the same time, managing processes and relations in sports is a very extensive field of research, which offers plenty of modes of specialized training and education for individuals, groups and sports entities, especially those which consider the sports industry as a profession that has a necessity of managing.As an exceptionally growing business segment, sports management employs a serious number of human resources, generates a huge volume of economic activities and processes, and affects in a positive way the determination and accumulation of peoples'life quality. Initially considering the general interest and need of Sports management, through defining the most important aspects of its long-founded management, the research effort will focus on the opportunities for professional development in the field of sports management. The fundamental factors that determine the theoretical-empirical approach to sports management on one hand, as well as the opportunities available for professional development of educated individuals, groups and entities in this segment on the other hand, will be integrally treated in order to present future directions and recommendations for more extensive outreach and development. Therefore, the paper will pay particular attention to the most important aspects related professionals who are integrated in the sports world and that effectively and efficiently build careers using different aspects of management.
\end{abstract}

Key Words: management, sports, opportunities, sports management, professional development

\section{Introduction}

Sports management as a rapidly growing field of knowledge, skills, experiences and capabilities, attracts growing attention among theorists and further on undoubtedly among practitioners in this area. An important part of human resources are attracted to sport, considering it as any other profession.In todays' complex environment, it is not enough to guarantee success in the profession, which is embodied by the behavior and interests of owners and managers of sports institutions, which in first line have a strong business orientation towards sport, and secondly are the aspects that point out their attraction and passionate interest in sports. Depending on the nature of sport, access to it and the system of integration of its participants, management models can cover starting from entrepreneurial activities that include profit activities, such as the management of the sports center, but can be also more geared towards integrated management of a particular sports program. From their dominant orientation, management activities are differentiated to perform functional elements of a chain of sports elements and processes, up to integrated, holistic management, where all aspects of the management of sports as a business should be applied in daily operational activities that often occurs in a number of sporting facilities or certain sports organizations.

\section{The function and role of sports and sports management}

As a growing and propulsive activity the industry, which treats the area of sports is booming and becoming a relevant segment for analysis and targeting, especially since it has become increasingly dominated by the business models for its management. According to studies conducted by the U.S. by the Association of manufacturers of sports products and their report issued in 2008 (SGMA, 2008), the number of people who have joined a health club in 2007 reached a number of 42.7 million, which in comparison to 1990 has increased for 21 million. At the same time, more than $72 \%$ of the children at an age of 11 years in the U.S. in 2008 were 
engaged in team sports. The women's basketball league in the United States attracts approximately 2 million fans each season, as opposed to approximately 20 million fans who attend on average during the regular competitions throughout the season in the NBA.Considering the evolution and looking on the historical development of science in sports management, its foundation is recorded in the late 60s of last century, especially by emphasizing the need for specially trained and educated staff that would be activated in the segment of sports management in order to proactively identify and meet the needs of each category of sports activity. Therefore, given the professional opportunities for individual, group and institutional training, with extensive knowledge and skills in this area, a challenge is imposed for systematic management of sport. Sports management is fairly young as an academic discipline (Chaplin, 2006), which can be defined in different ways and usually is a combination of skills related to planning, organizing, delegating, controlling, budgeting, management and evaluation in the context of the organization or department whose primary products or services are related to sports (Parks et al. 2007).Sports itself can involve a wide range of activities, encompassing particular segments of the sports industry that is increasingly focused on attracting consumers, which should be undoubtedly managed, especially given the fact that sports management is a multidisciplinary field that integrates the sports industry and management (Lussier et al. 2009).

It is extremely necessary to make a more detailed model of connecting management and sports, which is a dimension that often, especially in the past was the part where failure encountered, and in particularly when there was no adequate opportunity to recognize the great importance of the sports industry considering modern way of life, which is an aspect still even today partially present. Some of these biases are based on the simple view of sport, associated with activities that are related and based on leisure, recreation and apart from everything considered as entertaining activities. Considering certain circumstances and context, sometimes sports aspects are treated unfairly with less seriousness and importance. Reality is very different in a sense that sports in modern conditions is an extremely important business segment, which employs a huge number of people, generates huge volumes of economic activities, a segment which is used to evaluate and assess the quality of life of the population. From the large number of research efforts in terms of dimensions in sports management the following deserves attention in the categorization of four factors (Wuestand Bucher, 2005) which analyses and conceptualizes sports management through the following components:sports world, managing sports experience, organized sports and Sports enterprise. Basically, all these factors influence the formation of different aspects of sports management, through their interdependence and mutual conditionality, shown in the following Figure 1.1.

Throughout the entire evolutionary expansion, developed were and still are exiting a great number of professional organizations that bring together professionals from the field of sports management. The potential growth of organized sports and the need for professional sports administrators was mentioned for the first time in 1957, in a letter from O'Malley, the chairman and major shareholder of the baseball club "Dodgers ", to Dr. James Mason, who was a member of the Ohio University, USA at that time. That initial impulse resulted in the establishment of the first official program for postgraduate studies that provided an integrated preparation for jobs in the sports industry since $1966^{\text {th }}$. The evolutionary path of science related to sports management then continued in the founding of the Organization of Sports Management Resources Science and SMARTS, within the University of Massachusetts in 1970, which basically, is the base for creating the most important institution related to promotion of sports management and encouraging more activities in that particular area of research, professional applicative papers and professional development within this narrow specialized area, which resulted in the founding of the North American Organization for Sports management (NASSM), constituted in 1985, furthermore, just two years later followed by the publication of the Journal of Sports management.

Figure 1.1. Four factors in the analysis of sports management

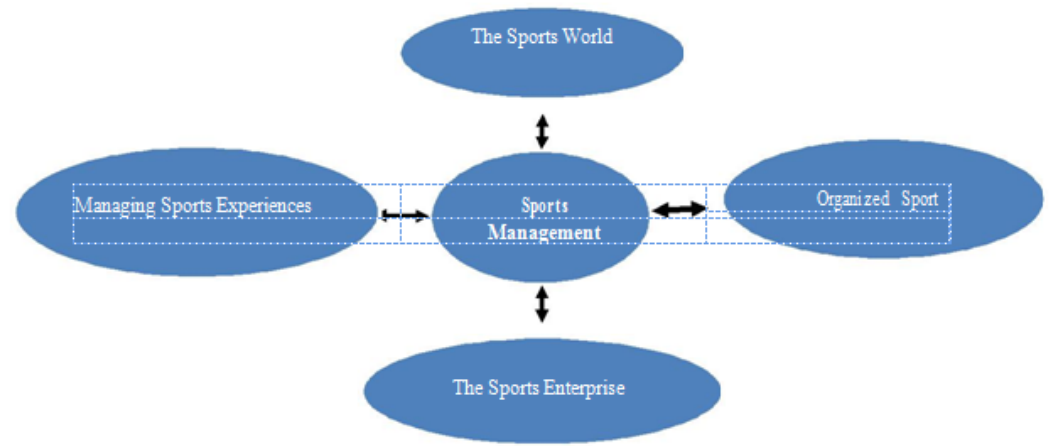

Source: Wuest, DA, Bucher, CA, (2005)Foundations of Physical Education, Exercise Science, and Sport, $15^{\text {Th }}$ edition, McGraw-Hill Humanities / Social Sciences / Languages, Boston, p.482 
The revolutionary activities in setting the grounds of modern sports activities and procedures which are necessary to be managed, are reflected through the initiatives in this area that are carried out through the years, until today (Parks et al., 2007). In this sense, according to NASSM a proper definition of sports management was set where it is considered to be "a field of research that offers specialized training and education required for individuals who are looking for a job in any part of the industry " (sports industry), ( Ziegler, 2007). In the 80s of the last century existed approximately twenty programs concerning the field of sports management in North America, which grew until 2000 up to2001(Parkhouse et al., 2001). One of the main reasons for the rapid increase of the number of academic programs in the field of sports management is the recognition that the value of sports depends on the way sports is managed (Chaplin, 2006).Considering the affirmation and wider popularization of sports management, recently the World Association for Sports management (World association for Sports management) has been created, more precisely in 2012 which is comprised of six core sports organizations around the world such as: the North American, the European, Australia and New Zealand, Asian, Latino and Afro-American organization for sports management.

\section{Perspectives for professional development in the field of sports management}

The development of science in sports management has developed along with several different opportunities for professional development, which is a dimension which rises from the acknowledge that in sport, treated as a business segment, managers determine the desired organizational performance, which are necessary to reach in the sports field. Therefore, programs in the field of sports management educate and prepare human resources for diverse management positions in areas such as university athletics, professional teams, fitness centers, recreation centers, training, managing various sports bodies, organizations and institutions, responsibilities in the area of marketing, youth sports organizations, and the production and trade of sports products. The most important modalities of building a career in the sports industry are presented in the following Table 1.1. and Figure 1.2.

Based on this categorization is important to distinguish the nature of the areas include career development, as well as the dimensions of professional development in the field of sports management, particularly in terms of highlighting the following : sports administration, sports clubs and centers, sports facilities, sports/leisure services, sports marketing, sports communication (Wuest, 2005)

Figure 1.2. Opportunities for professional development in the field of sports management

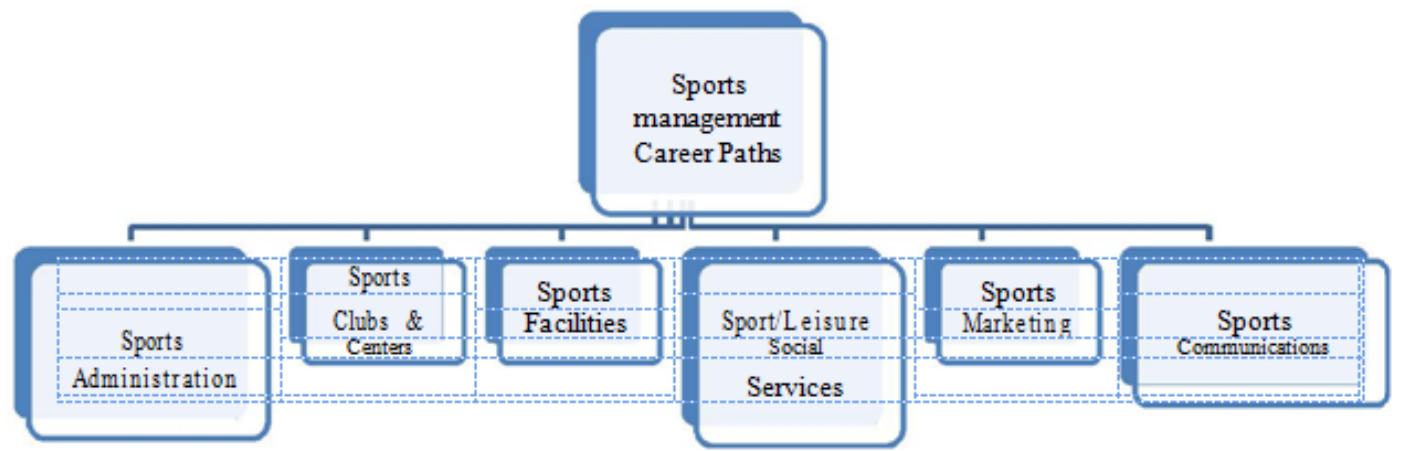

Source: Wuest, DA, Bucher, CA, (2005), Foundations of Physical Education, Exercise Science, and Sport, 15th edition. ed. McGraw-Hill Humanities / Social Sciences / Languages, Boston, p.484.

Table 1.1. Examples of careers in sports management

Athletic directors and their assistants hold excellent administrative jobs in college sports management. Every college needs an athletic director. Another collegiate position is sports information director. These profesionals are responsible for managing and distributing information about their college teams.

Stadiums and arenas need general managers, business managers, operations managers, box office managers, and event managers to run the their organizations. These jobs are exciting if you like to help produce live sports events.

Sports marketing agencies and independent agents represent athletes, handaling the business side of affairs for the athlete.

Sports broadcasting includes careers in daliy sports news programs, all-sports radio, and live game broadcast. All-sports radio stations have become very popular and are an excellent place to find an internship. The internet has opened up positions managing Web sites and providing statistical data for sports teams.

Recreation management is a broad term for carrers such as athletic directors at Community Centers, directors of public parks and recreation, workers in leisure fields such as fitnes centers, and directors of activities at resorts. 
Sporting goods manufacturers need employees in sales, operations, human resources, and finance.

The most obvious career path is working in professional leagues, Major league Baseball, The National Football League, the National Basketball Associations, and The National Hockey League.

\section{Source: Lussier R., Kimball D. (2009), Applied Sports management Skills, Thomson Learning. USA p.4}

The field called sports administration or administrative positions in the field of sports offers countless opportunities for education and professional development. In the field called sports administration or administrative positions related to the segment of sport, there are countless opportunities for education and professional development. Thus, at every level of education and professional development differences in the approach considering the regulation of this dimension could be distinguished such as:

$\square$ At the level of high schools, there are administrative positions in the field of sports management and, depending on the size of the school and its sports orientation, positions arise such as sports manager and even expanded sports associations, including, beside the sports manager, an assisting sports manager as well.

At the level of college or universities, there are more opportunities, and the number of administrative positions and the specific duties depend, to a large extent of the nature and size of the sports program. The most important administrative position in the field of sports management is the sports manager, deputy manager and assisting sports manager. Other positions that might be found in the faculty sports program are financial manager, marketing manager, recruiting coordinator, coordinator for regulation, coordinator of academic advising, etc.

The basic conclusion in determining the profile of activity concerning sports managers at every level of education, suggests that in the educational institutions which have developed a greater complexity in its performance, the sports manager is responsible for performing a countless number of tasks and responsibilities which treat the model of management in sports. In such organizations and educational institutions, sports managers deal with managing the growing volume of complex activities, processes and relationships, ranging from supervising coaches and their assistants, to organizing a system for matches, monitoring changes in relevant legislation, preparing the criteria for the organization of a regular diet for the athletes, up to their security, and all this by relying on the extensive help of their associates.

Compensation for the main actors in sports management - those holding the titles in sports administration, directly depend on the size and character of the responsibilities of the sports program. In the modern market economies, fees for sports managers are ranging from $\$ 25,000$ to $\$ 100,000$. This is the most serious indicator for the treatment of sports management in a society reflected in the reward for individuals who, despite their strong desire to be in touch with sports and work with athletes, feel the need for adequate financial satisfaction for the invested efforts and energy.

\section{Profile of professional staff in the field of sports management}

Considering modern terms, a growing number of companies from all business areas stimulate the organization of recreational and expert sports opportunities for their employees, in appropriate structured sports programs. The number of companies that are serious and integrated on long term considering sports as an element within their daily existence and activity is growing. With the proliferation of these programs the need for building qualified professionals who would take planning and implementation of such activities, processes and relationships as well as experts in sporting and recreational aspects, present in large companies is emphasized. The responsibility of these sports managers involves performing a series of responsibilities, among which in particular stands out the establishment of detailed program activities, organizing sports teams, scheduling of events, providing training, supervision of staff, etc. The tendency of increasing corporate recreation leads to opening more opportunities for the establishment of qualified sports professionals

The managers of sports facilities considering their working profile, can be found in various contexts of their employment, but traditionally managers of sports facilities are usually employed directly after graduation, considering this as one of the structural segments of society which are nationally needed, in the facilities of the local administration, commercial facilities such as sports centers, swimming pools and water parks, golf clubs, hockey playgrounds and more. With the increasing number of fitness centers and sports centers increases the potential of individuals who have an interest and professional orientation for managing sports facilities. Depending on the size of the object and details of its program, the number of individuals who assist sports managers can vary from independent execution of responsibilities, to a state in which the sports manager will be assisted by an assistant or even other staff that will work directly under his control.

In this sense, one of the main responsibilities of managers in sports the safety of individuals who use the services at the facility, which includes assurance that the facility and equipment is in proper order 
considering the safety and health of everyone playing sports, as well to ensure that it is in compliance with the required standards governing this area. Expert knowledge regarding the proper functioning of the facility, the health and hygiene conditions are extremely important for each individual. Therefore, in the institutions where sports matches are held, such as stadiums, theaters etc. the manager should ensure the application of the policies concerning operational guidelines in order to ensure the safety of visitors and the participants. Also, they need to manage the business aspects of the institution, which at the end of the year impose strong potential impact on the financial success or failure of the same.

Sales of sports apparel, athletic footwear, and licensed sports goods increases worldwide, given the extent of its presence and the degree of influence, can be counted in billions. With increased public interest in sport, fitness and sports activity sales are stimulated, and therefore stores for sports equipment and even schools, faculties and universities that have major athletic events, have become very powerful. Job opportunities and professional development in the area of sales of sports equipment, or as a sales manager of sports nutrition, beverages and supplements significantly increased in recent years and this trend is expected to continue and grow in the future.

In the U.S., many organizations, such NCAA, Women's Sports Foundation, the Olympic Committee allows students which have interest acquire a practice in this field. The increasing interest in the management of sports in the world can be seenas well in the role of telecommunication media such as television, radio, newspapers and magazines, which have contributed to the afirmation and growing number of career opportunities in sports communication media. In the last decade there has been growing sports events coverage by the media, which is still rising, there are even broadcasts of sports that traditionally are not on the list of most popular, such as bodybuilding, bowling etc.

Today, it is normal to have specialized channels that broadcast only sports events and live shows dedicated to the sport. The growth of the role of the internet opened countless webpages that on a daily basis and in real time disseminate the latest information from the sports world. The sports media around the world represent an excellent opportunity for a career that is very popular considering the job opportunities that are presented on radio and television stations, newspapers, internet portals and more. Therefore, a number of indivuduials use their skills to become entrepreneurs in the field of sports, developing services and products to meet the needs and interests of the people. The broad area of sports education and sports science offers great entrepreneurial opportunities that motivate and encourage.

In modern terms, one of the most noticable entrepreneurs in the field of sports are personal trainers. These professionals work on one-one base with clients, designing and implementinga fitness program that is specially designed, taylored and adapted to the needs of the client. Personal trainers usually visit clients at home or in the sports center where exercises are performed, in order to continuously monitor their workouts. A very large part of the population that is interested in improving their health and physical condition, willing to pay the professionals who will learn more skills that are needed to increase their level of health. Programs of personal trainers can be focused on assessing and improving their level of fitness and endurance, creating guidelines for nutrition, stress management, weight loss etc.Some profesionals that have more experience can be consultants on various Internet sites for health clubs, training staff and providing advice concerning diets, advice on health promotion etc.

\section{Professional opportunities in sports management in Macedonia}

In Macedonia, as a young and open market economy, the field of sports management is a topic that is discussed in the last decade and it is becoming more attractive by increasing awareness of the role and importance of sports and sports management as a whole. Sports in all, gets a more important place in the Macedonian society, which gradually creates conditions for greater development opportunities for professional development in this area. The interest in studying sports management and the development of academical programs enable a detailed methodological and systematic way of approaching sports and sports activities, processes and relationships. In terms of educational programs that providean appropriate and detailed education of sports management, currently in Macedonia there are only two programs for postgraduate studies existing, focusing on sports management.

The most notable expansion in Macedonia since the independence, is currently experienced in club sports and partially representative sport, which in turn affects the tendency for developing greater professionalisation ofthose involved in sports in Macedonia. Efforts, engagements and intentions of the state to increase quality of sports is reflected in the creation of appropriatesportinfrastructure facilities, which impose the need of people who will actively managethose facilities in aself- sustainable manner, expected to grow even more both in the present and in the future. In Macedonian clubs, regardless which particular sports considered, they have a distribution of the most common positions that are structurally important for their existence and survival, presented in Table 1.2.

Along with professional sports positions, it is important to note that sports and recreation has indicated 
noticable growth, therefore a growing number of recreational facilities such as a variety of fitness facilities, various recreational sports organizations, promoting of a variety of recreational opportunities, sports tourism and etc. In the area of sports there are many individuals who are involved and which integrate the activities related to sports and sports management. Although sports in Macedonia considered as a whole, faces a number of real challenges and problems, especially in the area of finance and the system of transformation of complete ownership of sports clubs, it is increasingly confronted with the necessity for a professional approach towards its management, starting from the national representations, club and individual sports on one side, and all aspects of recreational sports, on the other side. In this context, evidently the biggest growth of awareness of the importance of sports and sports life and the accepted reality that sport and management must be handled systematically, relying on specialized experts trained in many areas of life sports, such as sociologists, psychologists experts in teamwork, role playing sports etc.

Table 1.2. Common jobs in Macedonian sports clubs

\begin{tabular}{|c|c|c|}
\hline & Sports activities & Sports management activities \\
\hline & & President of the Board of Directors \\
\hline & & Chief Executive Officer \\
\hline & & Non-executive directors \\
\hline & & Administrative Coordinating Body \\
\hline & & President \\
\hline & \multirow[t]{2}{*}{ coach } & Vice President \\
\hline & & \multirow[t]{2}{*}{ General Secretary } \\
\hline & \multirow[t]{2}{*}{ assistant coach } & \\
\hline & & Sports director \\
\hline \multirow[t]{15}{*}{ Sports Clubs } & doctor & \multirow[t]{2}{*}{ Coordinator of Youth } \\
\hline & \multirow[t]{2}{*}{ physiotherapist } & \\
\hline & & \multirow[t]{2}{*}{ Board Member } \\
\hline & \multirow[t]{2}{*}{ Coaching Youth } & \\
\hline & & \multirow[t]{2}{*}{ Director } \\
\hline & Coaching the goalkeepers & \\
\hline & \multirow[t]{2}{*}{ Athletic Coach } & Deputy director \\
\hline & & \multirow[t]{2}{*}{ Marketing Manager } \\
\hline & \multirow{2}{*}{ Doctor } & \\
\hline & & Web-Coordinator \\
\hline & & Professional Staff \\
\hline & & Head of professional staff \\
\hline & & Assistant \\
\hline & & Coordinator of professional administrative work \\
\hline & & Economist \\
\hline
\end{tabular}

Source: Adopted according to the organizational structures of several sports clubs in RM, 2014

\section{Conclusion}

In the field of sports and sports management, especially worldwide, there are many diverse opportunities for professional development, which is reflected through the most illustrative conclusions following below as a result of the overall research process:

1. As a specialized scientific field, sports management has been developing intensively in the last thirty years and still shows a positive trend of growing, which is expected to continue at the same pace in the years to come. Sports are a very serious industry that generates huge revenues, expressed through billions of dollars and euros worldwide, and that in itself means a lot of business opportunities. World literature in the field of sports provides a myriad of information on possible directions and tendencies of development of quality in sports and sports professionals, allowing managers a serious base on information for their further research and analysis.

2. With the development of awareness concerning sports, the increasing sports success and interest of the population thereof, sports workersa higher attractiveness on one hand and on the other there is a need to establish new specialized jobs for resourcesthat will possess knowledge, experiences and skills in the field of sports management. In this sense, worldwide there are many programs that provide appropriate education for prospective staff and continuous areformed new ones in accordance to the compliance requirements and guidelines for development of specific types of sports.

3. In developed market economies, a growing number of people are involved professionally, in the field of sports and not just as athletes, but especially in the management of different processes, activities, events, human resources and finished products associated with sports. As a result of this momentum, the need for 
systematic management of all elements of sports emphasizes its importance, oriented towards long-term success and benefit, not only for the sports industry, but also for the health and well being of the involved individuals, groups and sports institutions.

4. Regardless of the acknowledgement whether it is a national team, club events or individual sports or even the recreational segment of sports andhealthy living, the entire sports infrastructure, sports marketing, media and communication especially in the area of sports, emphasizes the necessity of intense and methodical rounded education and vocational training, which undoubtedly must be continuously managed

5. In the Republic of Macedonia traditionally there is still a lack of professionalism and specialization when it comes to sports management. Knowledge, skills and overall professional education in this field is still limited, but there are serious examples of positive steps made noticed, considered as early movements in the right direction, especially visible in certain clubs or national teams .

6. In our country, there is still a lack of serious, multiple and interdisciplinary analytical data and information concerning the representation, and level of significancet for the reached level of development of sports management. In this sense, the emphasis isthatsports and its proper managementhave a strong positive impact on the overall quality of life, thus the necessity of increasing efforts is stressed, to successfully implement which is not only an obligation of the state, but all municipalities, organizations and institutions, to the level of each individual.

\section{References}

[1]. Beech J.,Chadwick S.,(2004), Business of Sports management Financial Times Management,1 edition Bill, K., (2009). Sports management. In Active Learning in Sport. Exeter [England] : Learning Matters. Chaplin, L.,(2006),"Toward a Distinctive Sports Discipline", Journal of Sports management 20:1-21

[2]. Mahony D.F., Mondello M., Hums M.A., Judd M. (2006), "Recruiting and Retaining Sports management Faculty: Factors Affecting Job Choice", Journal of Sports management 20:414-430.

[3]. Parkhouse, B.L., Pitts, B.G. (2001). Definition, evolution, and curriculum. In B.L. Park- house (Ed.), The management of sport: Its foundation and application (3rd ed., pp. 2-14). McGraw-Hill. New York, NY.

[4]. Lussier R., Kimball D. (2009), Applied Sports management Skills, Thomson Learning. USA

[5]. Parks, J., Quarterman, J., Thibault, L., (2007). Contemporary sports management - 3rd edition, third. Ed. Human Kinetics. Wuest, D.A., Bucher, C.A., (2005). Foundations of Physical Education, Exercise Science, and Sports 15 edition. Ed. McGraw- 